\title{
In vitro health beneficial activities of Pumpkin seeds from Cucurbita moschata cultivated in Lemnos
}

\author{
Danai SakKa ${ }^{\mathrm{a}}$ And Haralabos C. Karantonis ${ }^{\mathrm{a}^{*}}$ \\ ${ }^{a}$ University of The Aegean, School of the Environment, Department of Food Science and Nutrition, \\ Metropolite Ioakeim 2, 81400 Myrina-Lemnos, Greece \\ ${ }^{*}$ Corresponding author \\ chkarantonis@aegean.gr \\ TEL: $+30-22540-83111$ \\ FAX: $+30-22540-83109$ \\ Received: 27 July 2014; Published online: 18 October 2015 \\ Invited paper from the $3^{\text {rd }}$ International ISEKI_Food Conference - ISEKI_Food 2014 - Bridging Training and \\ Research for Industry and the Wider Community - Food Science and Technology Excellence for a Sustainable \\ Bioeconomy
}

\begin{abstract}
Pumpkin seeds are commonly consumed in Greece. Although Cucurbita moschata is locally grown in Lemnos and is traditionally used in pumpkin pies, the seeds are currently discarded after consumption of the fruit flesh. The aim of the present study was to investigate the nutritional functionality of pumpkin seeds from Cucurbita moschata grown in Lemnos.

Cucurbita moschatas' seeds, raw or roasted, were appropriately extracted and the results are presented for raw versus (vs) roasted seed extracts. The phenolic content was expressed as $\mu \mathrm{g}$ gallic acid/g of seeds according to Folin-Ciocalteau assay $(370.3 \pm 19.1$ vs $551.0 \pm 22.0)$. Antioxidant capacity was expressed as equivalent amount for $50 \%$ scavenging in mg of seeds for DPPH (50.03 \pm 5.91 vs $25.82 \pm$ $6.77)$ and ABTS $(17.85 \pm 0.77$ vs $12.77 \pm 0.76)$ assays, and as $\mu \mathrm{mol}$ of trolox/g of seeds for FRAP (1.19 \pm 0.05 vs $2.50 \pm 0.23)$ and CUPRAC $(2.13 \pm 0.11$ vs $3.25 \pm 0.06)$ assays. Anti-inflammatory/antithrombotic and anti-diabetic activities were expressed as $\mathrm{mg}$ of seeds for $50 \%$ inhibition of platelet activating factor ( $0.62 \mathrm{vs} 0.15)$ and as $\mu \mathrm{g}$ of seeds for $25 \%$ inhibition of alpha-glycosidase (40.0 vs 61.0 ) activities respectively. Moreover, anti-atherogenic activity was expressed as the \% increase in lag time of human plasma oxidation (62.7 versus 163.2)

Raw and roasted pumpkin seed extracts exert anti-oxidant, anti-thrombotic/anti-inflammatory, antiatherogenic and antidiabetic activities. Cucurbita moschata seeds may represent a novel opportunity for development of functional foods, with a local interest in Lemnos that would contribute also to the regional public health improvement.
\end{abstract}

Keywords: Pumpkin seeds; Cucurbita moschata; Functional foods; In vitro nutritive value 


\title{
Abbreviations and/or nomenclature
}

\author{
ABTS: $\quad$ 2, 2'-Azino-bis-(3-ethylbenzothiazoline-6-sulphonic acid) \\ CUPRAC: Cupric Ion Reducing Antioxidant Capacity \\ DPPH: 2, 2-Diphenyl-1-picryhydrazyl \\ FRAP: $\quad$ Ferric Reducing Antioxidant Power \\ LDL: $\quad$ Low Density Lipoprotein \\ PAF: $\quad$ Platelet Activating Factor \\ PRP: $\quad$ Platelet Rich Plasma \\ $\mathrm{SA}_{50}$ : $\quad$ Equivalent amount for $50 \%$ scavenging \\ $\mathrm{IA}_{50}$ : $\quad$ Equivalent amount for $50 \%$ inhibition \\ $\mathrm{IA}_{25}$ : $\quad$ Equivalent amount for $25 \%$ inhibition
}

\section{Introduction}

The four principal quality factors in foods are appearance, flavor, texture and nutrition. Traditionally, the nutrition quality factor comprises major nutrients such as carbohydrates, fats and proteins, as well as minor components such as minerals, vitamins, fibers (Bourne, 2002) and the well studied phenolics or not extensively studied various others (Jiang \& Du, 2011; Koike, Li, Liu, Hata, \& Nikaido, 2005; Li et al., 2009) or still unidentified minor food compounds.

In the last decades many studies have revealed that minor food components such as various lipids (Demopoulos, Karantonis, \& Antonopoulou, 2003; Fragopoulou, Demopoulos, \& Antonopoulou, 2009; Nasopoulou, Karantonis, Detopoulou, Demopoulos, \& Zabetakis, 2014) and phenolics (Del Rio et al., 2013) exert beneficial effects in human health by preventing chronic disease development in humans such as cardiovascular diseases and diabetes type II.

In recent years it has been made clear that chronic diseases share common basic pathophysiological mechanisms such as inflammation, thrombosis and oxidative stress. Understanding of the processes of the above mechanisms would be helpful for the development of potential therapeutic approaches (Balagopal, 2006; Demopoulos et al., 2003; Kampoli, Tousoulis, Antoniades, Siasos, \& Stefanadis, 2009; Libby, 2007). Interestingly, a link between those pathophysiological mechanisms and nutrition has been established (Nomikos, Fragopoulou, \& Antonopoulou, 2007; Xanthopoulou et al., 2010).

Many plants, their extracts and isolated com- pounds have demonstrated a spectrum of biological activities and have been used as food supplements for various disorders (Kadam et al., 2012). One such plant, pumpkin is one of the vegetables that meet the requirements of healthy nutrition; it is a gourd-like squash of the genus Cucurbita and the family Cucurbitaceae. Pumpkins ( $\mathrm{Cu}$ curbita spp.) are of local importance in traditional agricultural systems. They are cultivated throughout the world for their food, seed oil and medicinal value. Cucurbita pepo (squash), Cucurbita maxima (winter squash) and Cucurbita moschata (musk pumpin) are the species mostly grown in Central Europe (Kadam \& Patil, 2014). The nutritional value of nuts is well recognized (Sabate, Ros, \& Salas-Salvado, 2006). Among various nuts, pumpkin seeds are commonly consumed throughout the world including Greece (Merrick, 1990). In Greece pumpkin seeds are consumed either raw or roasted as component of the Mediterranean Diet. Several studies have dealt with the beneficial effects of the consumption of pumpkin flesh (Caili, Huan, \& Quanhong, 2006), but limited studies exist on the pumpkin seeds.

Although Cucurbita moschata is locally grown in the Greek island of Lemnos and is traditionally used in pumpkin pies the seeds are currently discarded after consumption of pumpkin flesh. The purpose of this study was to evaluate the in vitro anti-oxidant, anti-thrombotic/antiinflammatory, anti-atherogenic and anti-diabetic activity of Cucurbita moschata seed polar extracts in order to examine the possibility of using the seeds as a novel ingredient for the development of functional foods of local importance, 
contributing to public health improvement in a sustainable way.

\section{Materials and Methods}

\section{$2.1 \quad$ Reagents and chemicals}

Folin-Ciocalteau reagent, di-sodium hydrogen phosphate dehydrate, absolute ethanol, acetone, and acetic acid were purchased from Merck (Darmstadt, Germany). Sodium carbonate anhydrous was purchased from SDS (Peypin, France). Gallic acid, 1, 1-Diphenyl2-picryl-hydrazyl (DPPH), Bovine serum albumin fatty acid free, $\beta$-acetyl- $\gamma$-O-hexadecylL- $\alpha$-phosphatidylcholine (PAF), methanol and chloroform were purchased from Sigma-Aldrich Co. (St. Louis,MO). Trolox, neocuproine and Iron (III) chloride hexahydrate were purchased from from Acros Organics (New Jersey, USA). 2, 4, 6-Tris (2-pyridyl)-s-triazine (TPTZ) was purchased from Fluka (Milwaukee, WI, USA). Ammonium acetate, sodium chloride, sodium dihydrogen phosphate dehydrate, sodium acetate, copper chloride dihydrate, were purchased from Penta (CZ Ltd., Chrudim, Czech Republic). 2, 2'-Azino-bis-(3-ethylbezothiazoline-6sulphonic acid (ABTS) was purchased from Applichem (Darmstadt, Germany). Potassium persulfate was purchased from Chem-Lab (Zedelgem, Belgium). Copper sulphate pentahydrate was purchased from Alfa Aesar (Ward Hill, MA). The enzyme of alpha-glucozidase was purchased from MP Biomedicals (Illkirch, France).

\section{$2.2 \quad$ Preparation of pumpkin seeds}

Pumpkin (Cucurbita moschata) fruits cultivated in the island of Lemnos in Greece were obtained from a local market at Myrina. The seeds were hand selected from the interior of pumpkins and were manually dehusked in order to avoid damaging the kernels. $50 \mathrm{~g}$ of husked seeds were rinsed with water, treated with $1 \mathrm{~g}$ of sodium chloride and roasted at $170{ }^{\circ} \mathrm{C}$ in a domestic oven. Roasted seeds were then dehusked. Raw and roasted dehusked kernels were kept at $-40{ }^{\circ} \mathrm{C}$ for further analysis.

\subsection{Extraction of the pumpkin seeds}

An amount of $25.0 \mathrm{~g}$ of pumpkin seeds raw or roasted were homogenized for $5 \mathrm{~min}$ in 250.0 $\mathrm{mL}$ methanol/water $70 / 30(\mathrm{v} / \mathrm{v})$ plus $2 \%(\mathrm{v} / \mathrm{v})$ acetic acid using an homogenizer (Ultra Turrax, IKA Werke, Germany). The suspension was left at room temperature under magnetic agitation for $15 \mathrm{~min}$ and was then centrifuged for $10 \mathrm{~min}$ at $2000 \times \mathrm{g}$ in a Hermle $\mathrm{Z} 383$ centrifuge (Hermle Labortechnik, Wehingen). The supernatant was collected in an Erlenmeyer flask, weighted and subjected to further separation into its hydrophilic and lipophilic components through a biphasic solvent system formation according to the method of Bligh and Dyer (1959) with slight modifications. Appropriate amounts of chloroform and water were added to the above collected supernatant to achieve a solvent ratio of chloroform/methanol/water equal to $1 / 1 / 0.9$ $(\mathrm{v} / \mathrm{v} / \mathrm{v})$. The mixture was stirred at ambient temperature for $15 \mathrm{~min}$ and then centrifuged for $10 \mathrm{~min}$ at $2000 \times \mathrm{g}$ for the separation of the two solvent phases of the biphasic system. The chloroform and water phase were collected separately in Erlenmeyer flasks, dried using a Lab Tech EV 311 Rotary evaporator (Lab Tech, Italy), and redissolved in a known volume of methanol/water $70 / 30(\mathrm{v} / \mathrm{v})$ plus acetic acid to $2 \%(\mathrm{v} / \mathrm{v})$. The extracts were stored under nitrogen atmosphere at $-40{ }^{\circ} \mathrm{C}$ until further analysis.

\subsection{Determination of total phenolic content}

Total phenolic content in the extracts of both raw and roasted pumpkin seeds was determined according to the method of Singleton and Rossi (1965) with minor modifications. Total phenolics assay was conducted by mixing 0.01 to 0.08 $\mathrm{mL}$ of extracts with $1.8 \mathrm{~mL}$ of distilled water and $0.1 \mathrm{~mL}$ Folin-Ciocalteu reagent. After that, samples were vigorously stirred and incubated for 2 min in the dark. Then a quantity of $0.3 \mathrm{~mL}$ of aqueous $\mathrm{Na}_{2} \mathrm{CO}_{3} 20 \%$ (w/v) was added and the samples were vigorously stirred and incubated at $40^{\circ} \mathrm{C}$ in a water bath for $30 \mathrm{~min}$. Absorbance was measured spectrophotometrically at $765 \mathrm{~nm}$, 
using a Spectrophotometer Lambda 25 (PerkinElmer, Norwalk, USA). A standard curve was prepared with gallic acid. Final results were given as $\mu \mathrm{g}$ gallic acid /g seeds. Every sample was tested in triplicate.

\subsection{Evaluation of the antioxidant capacity}

The antioxidant capacity of the extracts of both raw and roasted pumpkin seeds was assessed by the DPPH, ABTS, FRAP and CUPRAC assays.

\section{DPPH Assay}

The capacity of the pumpkin seed extracts to scavenge the free radical of DPPH was assessed by a modified method of Abe, Murata, and Hirota (1998). An aliquot of the extracts (0.05 to $0.15 \mathrm{~mL}$ ) or appropriate standard solution of trolox was diluted with methanol up to 1.8 $\mathrm{mL}$. Then, $0.2 \mathrm{~mL}$ of $0.6 \mathrm{mM} \mathrm{DPPH}$ reagent in methanol was added, followed by vigorous stirring. After standing for $15 \mathrm{~min}$ in the dark, the absorbance was measured spectrophotometrically at $515 \mathrm{~nm}$ against a reference sample containing methanol instead of a sample aliquot.

The results were expressed as a $\mathrm{SA}_{50}$ value that represents the amount of pumpkin seed in $\mathrm{mg}$ whose extract was able to scavenge the radical of DPPH by $50 \%$. That amount was also expressed as nmol of trolox using the standard trolox solutions assayed at conditions similar to the sample extracts. Every sample was tested in triplicate.

\section{ABTS assay}

Determination of ABTS radical scavenging activity of extracts was performed by the method of Re et al. (1999) with minor modifications. ABTS radical cation $\left(\mathrm{ABTS}^{+\bullet}\right)$ was generated by the oxidation of ABTS with potassium persulfate $\left(\mathrm{K}_{2} \mathrm{~S}_{2} \mathrm{O}_{8}\right)$. The $\mathrm{ABTS}^{+} \bullet$ was produced by reacting $7 \mathrm{mmol} / \mathrm{L}$ stock solution of ABTS with $2.45 \mathrm{mmol} / \mathrm{L}$ potassium persulphate (final concentration). The $\mathrm{ABTS}^{+\bullet}$ solution was diluted (with distilled water) to an absorbance of $0.7 \pm$ 0.05 at $734 \mathrm{~nm}$. Aliquots of raw and roasted pumpkin extracts (0.01 to $0.12 \mathrm{~mL}$ ) or appropriate amounts of trolox standard solution were dried under a stream of nitrogen followed by addition of $2.5 \mathrm{~mL} \mathrm{ABTS}^{+} \bullet$ and were vigorously stirred. Samples were incubated for $15 \mathrm{~min}$ in the dark at ambient temperature and the absorbance was measured spectrophotometrically at $734 \mathrm{~nm}$. The ability of the extracts to scavenge the ABTS free cationic radical was evaluated relative to the reference sample that did not contain any extract. The results were expressed as a $\mathrm{SA}_{50}$ value that represents the amount of pumpkin seed in mg whose extract was able to scavenge ABTS $^{+} \bullet$ by $50 \%$. That amount was also expressed as nmol of trolox using standard trolox solutions assayed at conditions similar to the sample extracts. Every sample was tested in triplicate.

\section{FRAP Assay}

The reducing potential of the sample was determined using the FRAP assay as described by Benzie and Strain (1996). The method is based on the reduction of the $\mathrm{Fe}^{3+}$ - tripyridyltriazine complex to its ferrous colored form at low $\mathrm{pH}$ in the presence of antioxidants. The FRAP reagent was freshly prepared daily and contained $0.2 \mathrm{~mL}$ of a $10 \mathrm{mM}$ TPTZ (2,4,6- tripyridy-s-triazine) solution in $40 \mathrm{mM} \mathrm{HCl}$ plus $0.2 \mathrm{~mL}$ of $20 \mathrm{mM}$ $\mathrm{FeCl}_{3} \bullet 6 \mathrm{H}_{2} \mathrm{O}$ plus $0.2 \mathrm{~mL}$ of $3.0 \mathrm{M}$ acetate buffer, $\mathrm{pH}$ 3.6. Aliquots of raw and roasted pumpkin extracts $(0.02$ to $0.12 \mathrm{~mL})$ were transferred in glass test tubes, dried under a stream of nitrogen and dissolved in distilled water to a final volume of $1800 \mu \mathrm{L}$, followed by an addition of $600 \mu \mathrm{L}$ of FRAP solution and vigorous stirring. The samples were incubated for $10 \mathrm{~min}$ in a $37{ }^{\circ} \mathrm{C}$ water bath and the absorbance was measured at 593 nm. A standard curve was prepared using different concentrations of trolox. The antioxidant activity of the pumpkin seeds was expressed as $\mu \mathrm{mol}$ trolox/g seeds. Every sample was tested in triplicate.

\section{CUPRAC Assay}

The reducing potential of the sample was determined using the CUPRAC assay as described by Apak, Guclu, Ozyurek, and Karademir (2004). Different volumes of the extracts were transferred in test tubes and were briefly dried under a stream of nitrogen. An ad- 
dition of $600 \mu \mathrm{L} \mathrm{CuCl}{ }_{2} \bullet 2 \mathrm{H}_{2} \mathrm{O} 10 \mathrm{mM}$ solution, $600 \mu \mathrm{L}$ neocuproine $7.5 \mathrm{mM}$ and $600 \mu \mathrm{L}$ buffer $\mathrm{CH}_{3} \mathrm{COONH}_{4} 1 \mathrm{M} \mathrm{pH}=7.0$ was followed and a final volume of $2400 \mu \mathrm{L}$ was reached with $\mathrm{dH}_{2} \mathrm{O}$. The samples were well stirred and incubated at room temperature for $30 \mathrm{~min}$. After the incubation the absorbance of the samples was measured at $450 \mathrm{~nm}$.

A standard curve was prepared using different concentrations of trolox. The antioxidant activity of the pumpkin seeds was expressed as $\mu \mathrm{mol}$ trolox/g seeds. Every sample was tested in triplicate.

\subsection{In vitro anti-thrombotic/anti- inflammatory activity}

The in vitro anti-thrombotic/anti-inflammatory activity of raw and roasted pumpkin seed extracts was evaluated on a Chrono-Log 500-Ca aggregometer (Chrono-Log Co., Havertown, PA, USA) connected to a computer (Aggro/Link software; Chrono-Log, Hawertown, PA), according to their ability to inhibit the thrombotic and inflammatory lipid mediator of platelet activating factor (PAF) towards human platelet rich plasma (PRP) as previously described (Karantonis et al., 2006). Aliquots of the extracts (0.1 to 5.0 $\mu \mathrm{L})$ and PAF ethanolic solution were evaporated under a stream of nitrogen and reconstituted in bovine serum albumin (BSA) $(2.5 \mathrm{mg} / \mathrm{mL}$ saline). After that, aliquots of $250 \mu \mathrm{L}$ of PRP along with stir bars were placed in siliconized glass cuvettes and were incubated for $15 \mathrm{~min}$ in the incubation wells of the aggregometer at 37 ${ }^{\circ} \mathrm{C}$. In the next step, the platelet response induced by PAF (10E- $8 \mathrm{M}$, final concentration) in human platelet rich plasma before (considered as $0 \%$ inhibition) and after the addition of various amounts of the examined samples was recorded by the aggregometer upon stirring at $1200 \mathrm{rpm}$. The amount of extracts required for $50 \%$ inhibition (Equivalent amount for 50\% inhibition; $\mathrm{IA}_{50}$ ) of PAF activity was calculated using the linear plot of the percentage inhibition, ranging from 20 to $80 \%$, versus different amounts of the samples. The results were expressed as mg of raw or roasted seeds. Each sample was evaluated in duplicate.

\section{$2.7 \quad$ In vitro anti-atherogenic activity}

In vitro antiatherogenic activity was evaluated by the human plasma oxidation inhibition assay according to Schnitzer et al. (1998) with minor modifications using a Spectrophotometer Lambda 25 (Perkin-Elmer, Norwalk, USA) equipped with an 8 position thermostated sample changer. Aliquots of raw and roasted pumpkin seed extracts $(0.020$ to $0.030 \mu \mathrm{L})$ were placed in UV-transparent disposable cuvettes (Brand, Wertheim, Germany) and dried under a stream of nitrogen. Then, $2200 \mu \mathrm{L}$ of phosphate buffer solution, $\mathrm{pH} 7.4,146 \mathrm{mM}$ in $\mathrm{NaCl}$ and $50 \mu \mathrm{L}$ of human plasma were added, followed by gentle shaking and incubation for 1 hour at ambient temperature. In the next step, the samples were placed into the thermostated chamber of the photometer and incubated for $10 \mathrm{~min}$ at 37 ${ }^{\circ} \mathrm{C}$ and the oxidation reaction was started by the addition of $250 \mu \mathrm{L}$ of $1 \mathrm{mM} \mathrm{CuSO}_{4} \bullet 5 \mathrm{H}_{2} \mathrm{O}$. The absorbance was continuously recorded for $3 \mathrm{~h}$ at $245 \mathrm{~nm}$ and at a stable temperature of $37{ }^{\circ} \mathrm{C}$. Lag times from the resultant sigmoid curves were calculated; time needed for the antioxidants to be oxidized, corresponding to the period of time that plasma resists oxidation. The percentage of the inhibition of in vitro plasma oxidation induced by the extracts was evaluated by comparing the lag time of each tested sample containing extract to a reference sample that did not contain extract. Every sample was tested in duplicate.

\subsection{In vitro anti-diabetic activity}

The anti-diabetic activity was determined by the alpha-glucosidase inhibition assay according to Vinholes et al. (2011). Aliquots of raw and roasted pumpkin seed extracts (0.020 to $3.5 \mathrm{uL}$ ) were transferred in polypropylene test tubes and dried under a stream of nitrogen. After that, 6.0 $\mu \mathrm{L}$ of a-glucosidase prepared in double distilled water (0.02 U per $\mathrm{mL}$; final concentration) and sodium phosphate buffer solution (PBS) $0.1 \mathrm{M} \mathrm{pH}$ equal to 6.8 were added to a final volume of $400 \mu \mathrm{L}$. The samples were incubated 


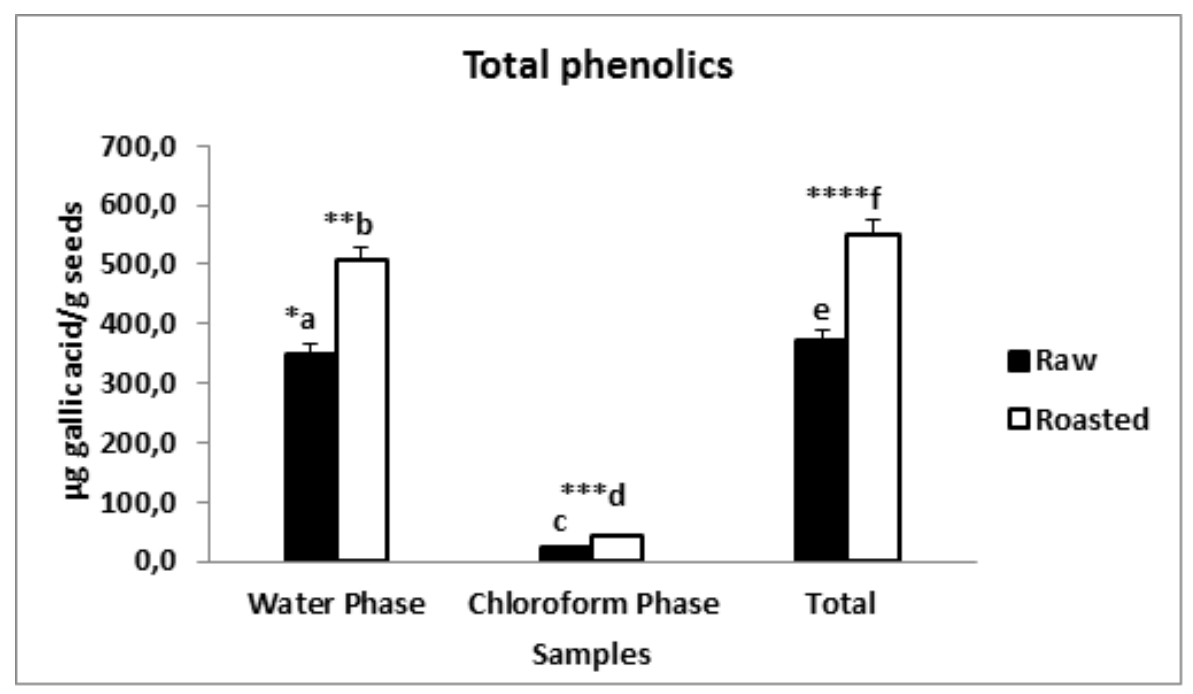

Figure 1: Total phenolic content for raw and roasted pumpkin seeds extracted by methanol/water 70/30 (v/v) plus $2 \%(\mathrm{v} / \mathrm{v})$ acetic acid and separated as hydrophilic components in water phase and lipophilic ones in chloroform phase. The results are expressed as mean $\pm \mathrm{SD}$ for triplicate determinations in water phase, chloroform phase and total extract. *: denotes significantly higher phenolic content compared to $\mathrm{c}$ and $\mathrm{d} .{ }^{* *}$ : denotes significantly higher phenolic content compared to a, c and d. ${ }^{* * *}$ : denotes significantly higher phenolic content compared to c. ${ }^{* * * *}$ : denotes significantly higher phenolic content compared to e. Differences with a value of $\mathrm{p}<0.05$ were considered statistically significant

for 10 min at $37.5{ }^{\circ} \mathrm{C}$. After the incubation step, $50 \mu \mathrm{L}$ of p-nitrophenyl glucopyranoside (pNPG) $3 \mathrm{mM}$, used as enzyme substrate, was added to begin the enzyme reaction with a final concentration of alpha-glucosidase equal to 0.02 $\mathrm{U} / \mathrm{mL}$. The mixture was incubated for $10 \mathrm{~min}$ at $37.5{ }^{\circ} \mathrm{C}$. The enzyme reaction was stopped by the addition of $800 \mu \mathrm{L} \mathrm{Na}_{2} \mathrm{CO}_{3} 1 \mathrm{M}$. The absorbance of the samples was measured at 405 nm.

For each different extract sample, a blank containing sample extract without alphaglucosidase, and a reference containing alphaglucosidase (without sample extract) were prepared. The results were expressed as the percentage inhibition of alpha-glucosidase activity and the IA25 values were determined as $\mathrm{mg}$ of seeds which inhibited alpha-glucosidase activity by $25 \%$. Each sample was tested in triplicate.

\subsection{Statistical analysis}

Data are presented as mean \pm standard deviation for triplicate determination or as mean for duplicate determinations. Statistical analysis was performed with SPSS version 21.0 (SPSS Inc, Chicago, IL). An independent t-test was performed to assess statistical significance. Differences with a value of $p<0.05$ were considered statistically significant.

\section{Results and Discussion}

\subsection{Total phenolics}

Phenolic compounds are associated with antioxidant activity and play an important role in stabilising lipid peroxidation (Yen, Duh, \& Tsai, 1993). Content of total phenolics in extracts of Curcubita moschata seeds was expressed as $\mu \mathrm{g}$ of gallic acid per $\mathrm{g}$ of seeds. Total phenolics in the water and chloroform phases of raw 


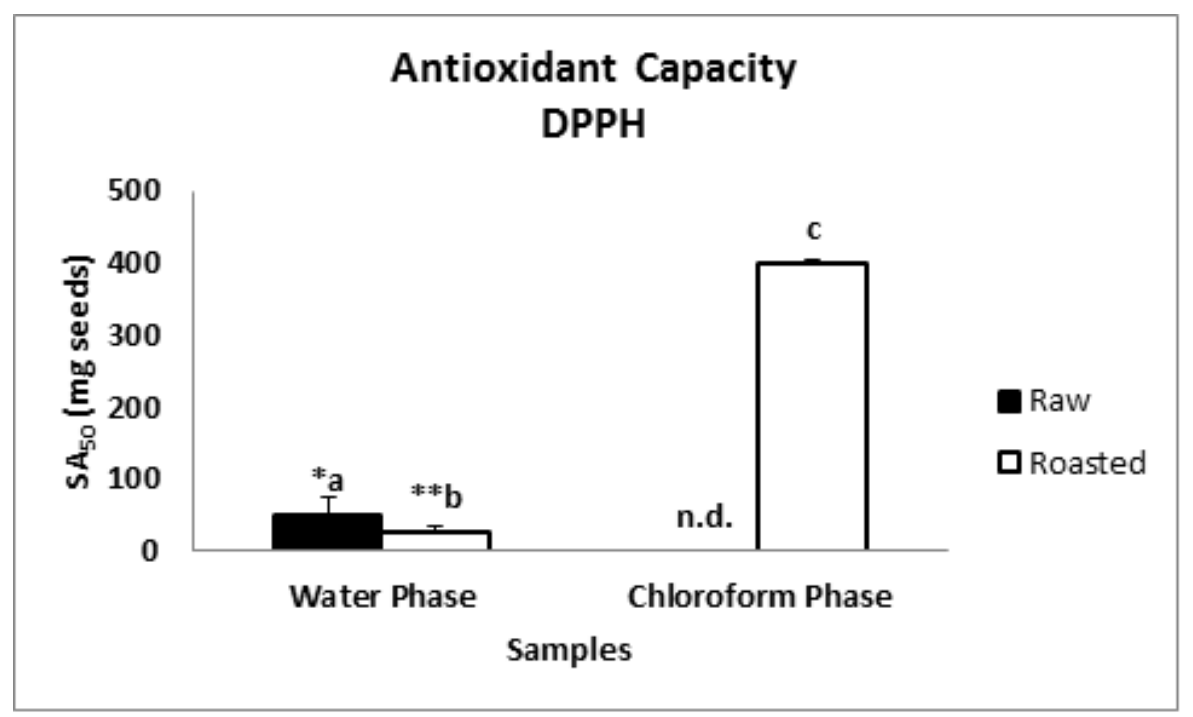

Figure 2: Antioxidant capacity as assessed by the scavenging of the DPPH (2,2-Diphenyl-1-picryhydrazyl ) radical. The results are expressed as mean $\pm \mathrm{SD}$ for triplicate determinations in water phase and chloroform phase for raw and roasted pumpkin seeds after extracted by methanol/water 70/30 (v/v) plus $2 \%(\mathrm{v} / \mathrm{v})$ acetic acid and separated as hydrophilic components in water phase and lipophilic ones in chloroform phase. $\mathrm{SA}_{50}$ : denotes the equivalent amount for $50 \%$ scavenging. n.d.: stands for not detected.*: denotes significantly higher antioxidant capacity compared to c. **: denotes significantly higher antioxidant capacity compared to a and c. Differences with a value of $\mathrm{p}<0.05$ were considered statistically significant

seed extract were $347.6 \pm 17.4$ and $22.7 \pm 1.7$ respectively, giving a total phenolic content for raw seeds equal to $370.3 \pm 19.1$ (Figure 1 ). On the other hand, total phenolics in the water and chloroform phases of roasted seeds were $506.8 \pm$ 21.9 and $44.2 \pm 1.0$ respectively, giving a total phenolic content for roasted seeds equal to $551.0 \pm 22.8$. (Figure 1). The results indicate that pumpkin seeds contain both lipophilic and hydrophilic phenolics. The hydrophilic phenolics in both raw and roasted seeds were higher compared to the lipohilic ones $(\mathrm{p}<0.05)$. Hydrophilic and lipophilic phenolics were significantly higher in roasted seed extracts compared to raw seed extracts $(\mathrm{p}<0.05)$, resulting also in a significantly higher amount of total phenolics in roasted compared to raw seeds $(\mathrm{p}<0.05)$ (Figure 1). Increased phenolics after heating have been previously been reported in fruit seeds (Soong \& Barlow, 2004). The authors suggested that the formation of phenolic compounds during the heating process might be due to the availability of precursors of phenolic molecules, by non-enzymatic interconversion between phenolic molecules subjected to the effects of temperature.

\subsection{Antioxidant Capacity}

The plethora of different antioxidants in various foods, especially fruits and vegetables, make it difficult to measure each antioxidant component separately. Therefore, several methods have been developed to evaluate the total antioxidant capacity in various food samples including $\mathrm{DPPH}$, ABTS, FRAP and CUPRAC assays.

\section{Antioxidant Capacity}

Results concerning the capacity of Curcubita moschata seed extracts to scavenge the free radical of DPPH were expressed as equivalent 


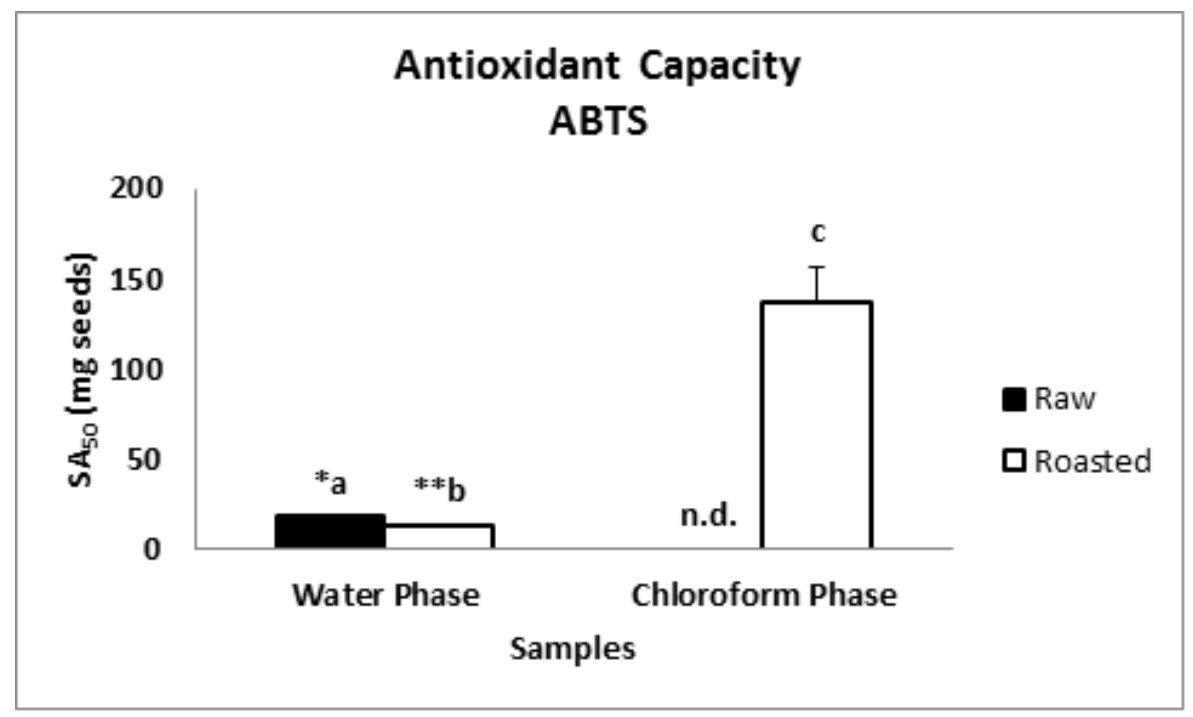

Figure 3: Antioxidant capacity as assessed by the scavenging of the ABTS (2,2'-Azino-bis-(3ethylbenzothiazoline-6-sulphonic acid) ) radical cation. The results are expressed as mean \pm SD for triplicate determinations in water phase and chloroform phase for raw and roasted pumpkin seeds after extracted by methanol/water $70 / 30(\mathrm{v} / \mathrm{v})$ plus $2 \%(\mathrm{v} / \mathrm{v})$ acetic acid and separated as hydrophilic components in water phase and lipophilic ones in chloroform phase. $\mathrm{SA}_{50}$ : denotes the equivalent amount for $50 \%$ scavenging. n.d.: stands for not detected. *: denotes significantly higher antioxidant capacity compared to c. ${ }^{* *}$ : denotes significantly higher antioxidant capacity compared to a and c. Differences with a value of $\mathrm{p}<0.05$ were considered statistically significant

amount in $\mathrm{mg}$ of pumpkin seeds for $50 \%$ scavenging $\left(\mathrm{SA}_{50}\right)$, meaning that a lower value of $\mathrm{SA}_{50}$ corresponds to a higher scavenging activity for the extract. In raw seed extract, the $\mathrm{SA}_{50}$ for the water phase was equal to $50.03 \pm 5.91$ (mg of raw seeds), while no scavenging activity was detected in the corresponding chloroform phase (Figure 2). On the other hand, in roasted seed extract, the $\mathrm{SA}_{50}$ value for the water and chloroform phases were equal to $25.82 \pm 6.77$ and $400.80 \pm 3.25$ (mg of roasted seeds) respectively (Figure 2). The above values of $\mathrm{SA}_{50}$ were equivalent to $26 \mathrm{nmol}$ of trolox based on a trolox standard curve for the assay. The results show that roasted seed extracts exerted significantly higher antioxidant capacity compared to the raw seed extracts $(\mathrm{p}<0.05)$ in terms of DPPH radical scavenging. This result is in accordance with the higher total phenolic content determined in roasted compared to raw pumpkin seed extracts.

\begin{abstract}
ABTS Assay
The same pattern was observed for the scavenging radical cation of ABTS. More specifically, in raw seed extract, the $\mathrm{SA}_{50}$ for the water phase was equal to $17.85 \pm 0.77$ ( $\mathrm{mg}$ of raw seeds), while no scavenging activity was detected in the corresponding chloroform phase (Figure 3). On the other hand, in roasted seed extract, the $\mathrm{SA}_{50}$ value for the water and chloroform phases were equal to $12.77 \pm 0.76$ and $137.38 \pm 19.38$ ( $\mathrm{mg}$ of roasted seeds) respectively (Figure 3 ). The above values of $\mathrm{SA}_{50}$ were equivalent to $33 \mathrm{nmol}$ of trolox based on a standard curve for the assay. The results show that roasted seed extracts exerted significantly higher antioxidant capacity compared to the raw seed extracts $(\mathrm{p}<0.05)$ in terms of ABTS cation radical scavenging. The results show also a higher capacity for scavenging the ABTS radical cation compared to the DPPH radical. This result is also in accordance with
\end{abstract}




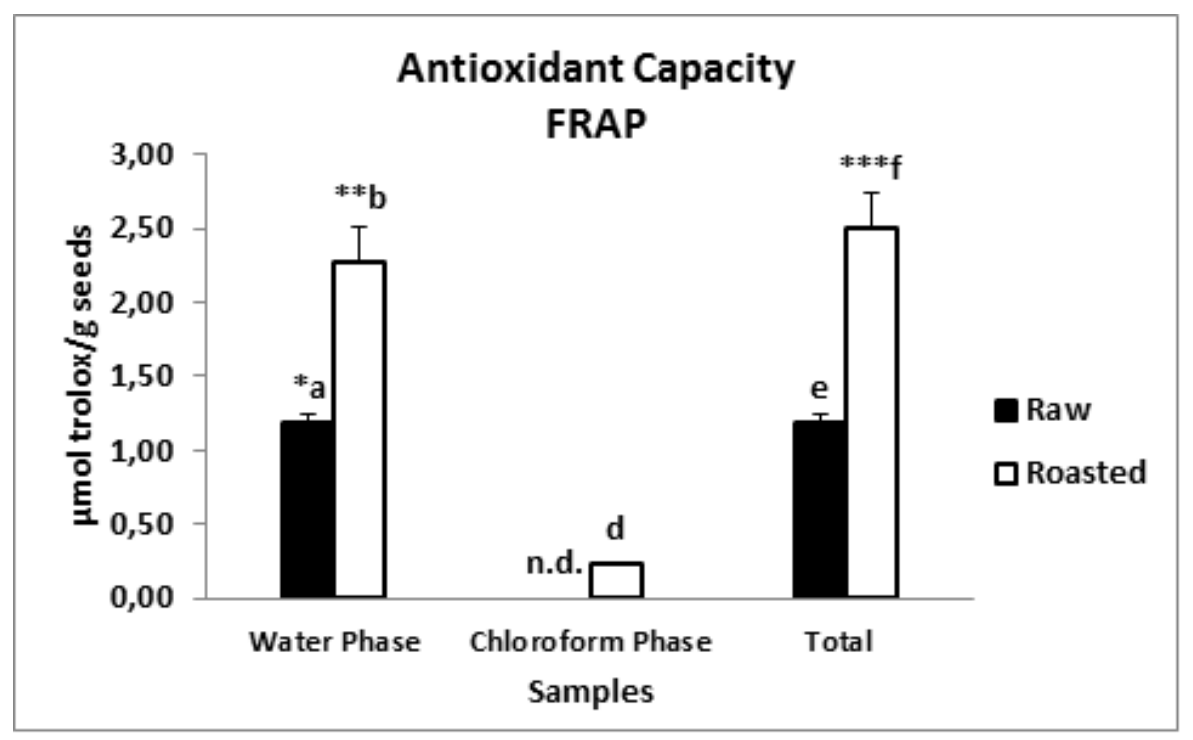

Figure 4: Antioxidant capacity as assessed by reduction of ferric to ferrous ions for raw and roasted pumpkin seeds extracted by methanol/water $70 / 30(\mathrm{v} / \mathrm{v})$ plus $2 \%(\mathrm{v} / \mathrm{v})$ acetic acid and separated as hydrophilic components in water phase and lipophilic ones in chloroform phase. The results are expressed as mean \pm SD for triplicate determinations in water phase, chloroform phase and total extract. n.d.: stands for not detected. *: denotes significantly higher antioxidant capacity compared to d **: denotes significantly higher antioxidant capacity compared to a and d. $* * *$ : denotes significantly higher antioxidant capacity compared to e. Differences with a value of $\mathrm{p}<0.05$ were considered statistically significant

the higher total phenolic content determined in roasted compared to raw pumpkin seed extracts.

\section{FRAP Assay}

The antioxidant activities of pumpkin seed extracts in terms of their capacity to reduce ferric to ferrous form of TPTZ were expressed as $\mu \mathrm{mol}$ trolox per $\mathrm{g}$ of seeds and are presented in Figure 4. In raw seeds, the estimated value from the FRAP assay was $1.19 \pm 0.05 \mu \mathrm{mol}$ trolox/g of seeds. This value comes from the water phase of the raw seed extract, since no antioxidant capacity was detected in the chloroform phase of this extract. On the other hand, antioxidant capacities in the water and chloroform phases of roasted seed extracts were $2.27 \pm 0.24$ and $0.23 \pm 0.01$ $\mu \mathrm{mol}$ trolox/g of seeds respectively. This gives a total antioxidant capacity for the roasted seeds equal to $2.50 \pm 0.23 \mu \mathrm{mol}$ trolox $/ \mathrm{g}$ of seeds. The results show that antioxidant capacities in terms of the FRAP assay were significantly higher in both phases of roasted seed extracts compared to those of raw seed extracts $(\mathrm{p}<0.05)$, resulting also in a significantly higher antioxidant capacity in roasted compared to raw seeds in total $(\mathrm{p}<0.05)$.

\section{CUPRAC Assay}

The antioxidant activities of pumpkin seed extracts in terms of their cupric ion reducing capacity were expressed as $\mu \mathrm{mol}$ trolox per $\mathrm{g}$ of seeds and are presented in Figure 5. Antioxidant capacities in the water and chloroform phases of raw seed extracts were $1.78 \pm 0.11$ and $0.35 \pm$ $0.03 \mu \mathrm{mol}$ trolox/g of seeds, respectively. This results to a total antioxidant capacity for raw seeds equal to $2.13 \pm 0.11 \mu \mathrm{mol}$ trolox $/ \mathrm{g}$ seeds. On the other hand, antioxidant capacities in the water and chloroform phases of roasted seeds were 2.85 \pm 0.05 and $0.40 \pm 0.01 \mu \mathrm{mol}$ trolox $/ \mathrm{g}$ of seeds,

\begin{tabular}{l|l|l|l} 
IJFS | October 2015 & Volume 4 & pages 221-237
\end{tabular} 


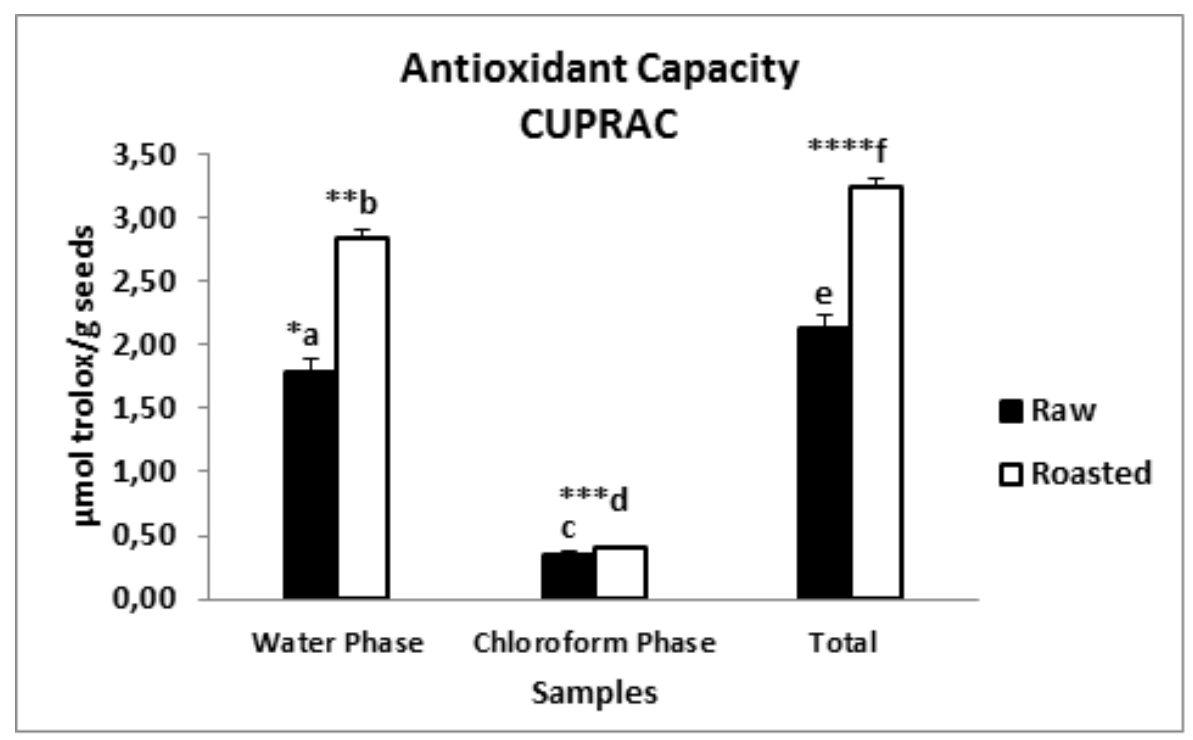

Figure 5: Antioxidant capacity as assessed by reduction of cupric to cuprous ions for raw and roasted pumpkin seeds extracted by methanol/water $70 / 30(\mathrm{v} / \mathrm{v})$ plus $2 \%(\mathrm{v} / \mathrm{v})$ acetic acid and separated as hydrophilic components in water phase and lipophilic ones in chloroform phase. The results are expressed as mean $\pm \mathrm{SD}$ for triplicate determinations in water phase, chloroform phase and total extract. *: denotes significantly higher antioxidant capacity compared to c and d. **: denotes significantly higher antioxidant capacity compared to a, c and d. ${ }^{* * *}$ : denotes significantly higher antioxidant capacity compared to c. $* * * *$ : denotes significantly higher antioxidant capacity compared to e. Differences with a value of $\mathrm{p}<0.05$ were considered statistically significant

respectively. This results in a total antioxidant capacity for roasted seeds equal to $3.25 \pm 0.06$ $\mu$ mol trolox/g seeds. The results show that antioxidant capacity in terms of the CUPRAC assay were significantly higher in both phases of roasted seed extracts compared to those of raw seed extracts $(\mathrm{p}<0.05)$, resulting also in a significantly higher antioxidant capacity in roasted compared to those of raw seeds in total $(\mathrm{p}<0.05)$. Oxidative stress plays an important role in ageing and the pathogenesis of chronic diseases such as atherosclerosis and diabetes (Arzamastseva et al., 2007; Giacco \& Brownlee, 2010). Many epidemiological studies suggest that consumption of a fruit- and vegetable-rich diet inversely correlates with the risk of chronic diseases. These chemoprotective effects are, at least in part, related to the antioxidant activities of phenolic compounds (Holt et al., 2009; Naelsen, Basu, Wolk, \& Vessby, 2006).

\subsection{In vitro anti-thrombotic/anti- inflammatory activity}

The in vitro anti-thrombotic/anti-inflammatory activity of pumpkin seed extracts were expressed as the equivalent amount, in mg of seeds, required for $50 \%$ inhibition of PAF activity $\left(\mathrm{IA}_{50}\right)$ toward human platelet rich plasma (PRP). This means that a lower value of $\mathrm{IA}_{50}$ corresponds to a higher inhibitory activity for the extract. The $\mathrm{IA}_{50}$ value for the water phase of the raw seed extract was equal to $0.62 \mathrm{mg}$ and was significantly higher compared to the value of $0.15 \mathrm{mg}$ that corresponded to the respective phase of the roasted seed extract $(\mathrm{p}<0.05)$ (Figure 6). No inhibitory activity was detected in the chloroform phases of both raw and roasted seed extracts (Figure 6). The results show the existence of hydrophilic minor compounds in both 


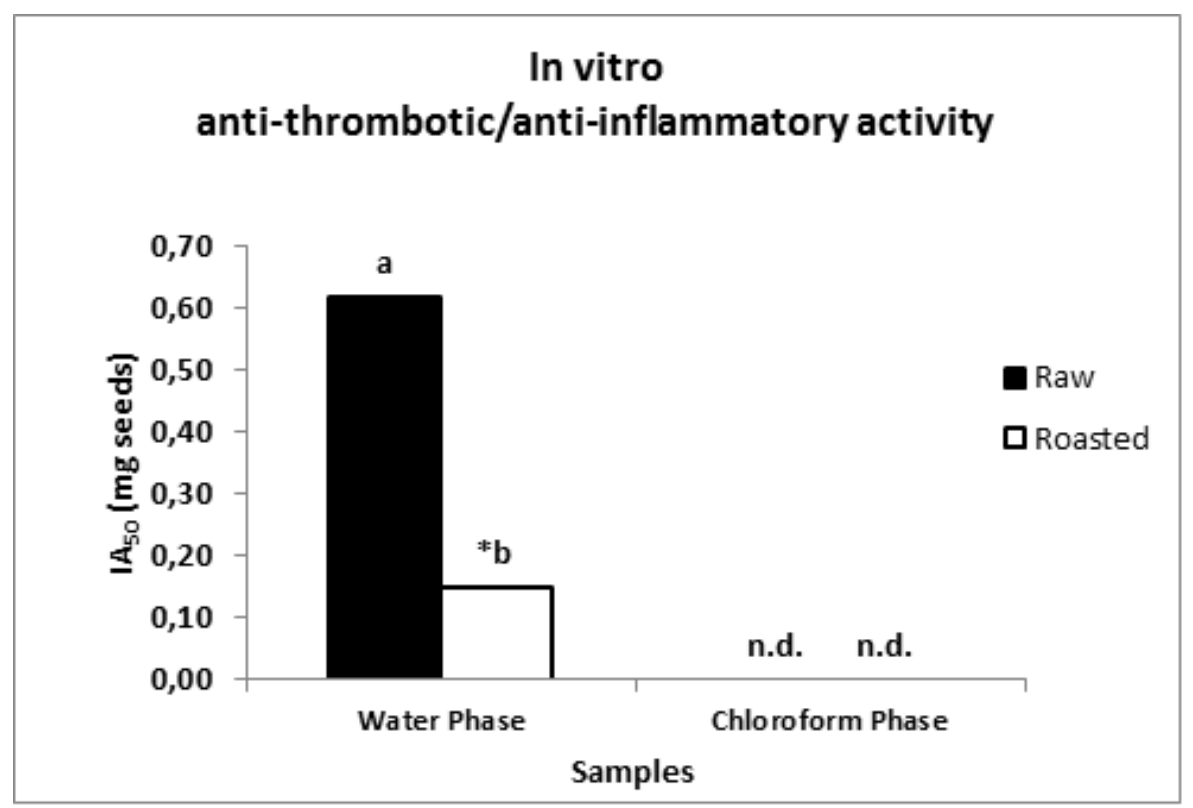

Figure 6: in vitro anti-thrombotic/anti-inflammatory capacity as assessed by inhibition of platelet activating factor (PAF) activity for raw and roasted pumpkin seeds extracted by methanol/water 70/30 $(\mathrm{v} / \mathrm{v})$ plus $2 \%(\mathrm{v} / \mathrm{v})$ acetic acid and separated as hydrophilic components in water phase and lipophilic ones in chloroform phase. The results are expressed as mean value for duplicate determinations in water and chloroform phase. $\mathrm{IA}_{50}$ : stands for equivalent amount for $50 \%$ inhibition. n.d.: stands for not detected. *: denotes significantly higher anti-thrombotic/anti-inflammatory capacity a. Differences with a value of $\mathrm{p}<0.05$ were considered statistically significant

raw and roasted pumpkin seeds that exert antithrombotic/anti-inflammatory activity in terms of PAF inhibition toward human platelets. A higher activity was detected in the water phase of roasted seeds compared to the respective phase of raw seeds $(p<0.05)$. These results mirror what was found for the total phenolic content and antioxidant capacity of the seed extracts.

A fruit- and vegetable-rich diet has also been inversely correlated with reduced inflammation (Holt et al., 2009). Platelet activating factor (PAF) identified as 1-O-alkyl-2acetyl-sn-glycero-3-phosphocholine (Demopoulos, Pinckard, \& Hanahan, 1979) has been recognized as one of the most potent lipid inflammatory and thrombotic mediator that activates various cells through its specific receptor, such as platelets (Demopoulos et al., 2003). Activated platelets are important contributors to thrombosis and inflammation, and represent an im- portant linkage between inflammation, thrombosis, and atherogenesis (Demopoulos et al., 2003; Fuentes et al., 2013; Gawaz, Langer, \& May, 2005; Rondina, Weyrich, \& Zimmerman, 2013). In vitro inhibition of $\mathrm{PAF}$ induced platelet activation from food components has been used as a research tool to investigate the nutritional value of those foods and their possible preventive effect against chronic disease development when consumed as part of a balanced diet (Karantonis, Antonopoulou, \& Demopoulos, 2002, 2006; Karantonis et al., 2008; Nomikos, Karantonis, Skarvelis, Demopoulos, \& Zabetakis, 2006; Nomikos et al., 2007). 


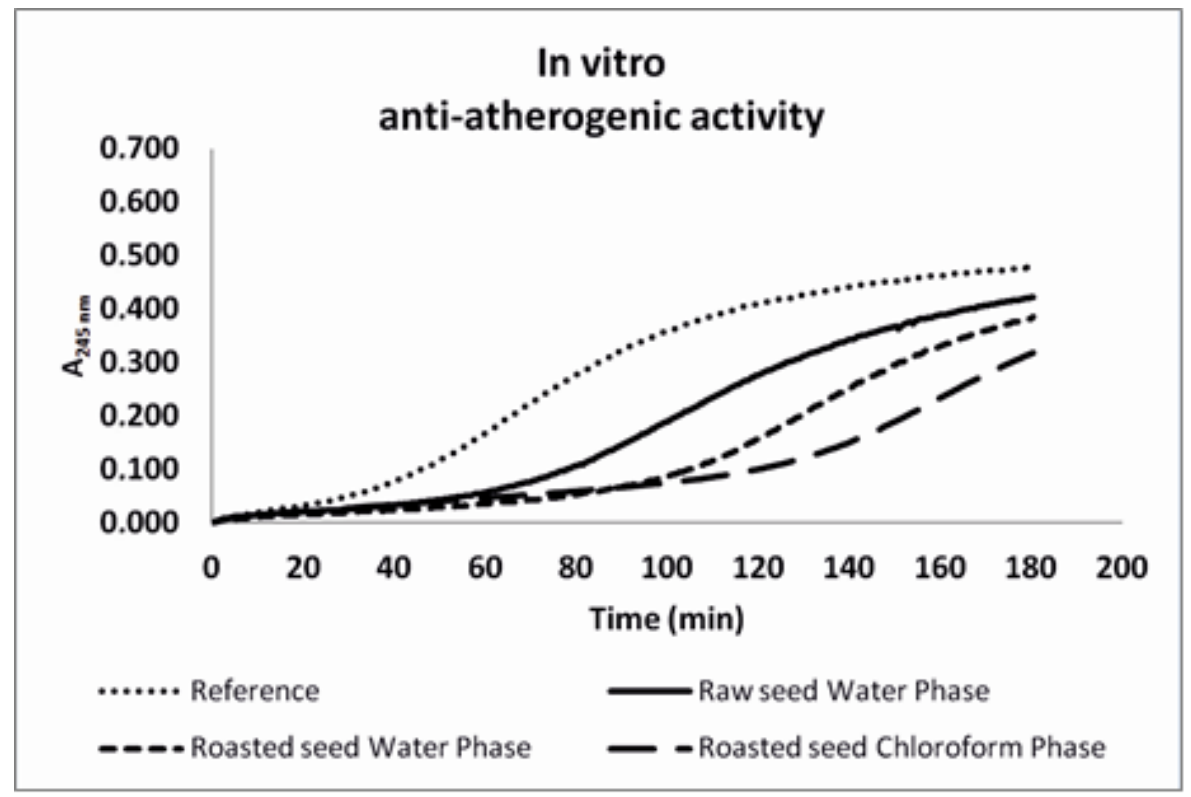

Figure 7: Representative graph for in vitro anti-atherogenic activity as assessed by inhibition of human plasma oxidation for raw and roasted pumpkin seeds extracted by methanol/water $70 / 30(\mathrm{v} / \mathrm{v})$ plus $2 \%(\mathrm{v} / \mathrm{v})$ acetic acid and separated as hydrophilic components in water phase and lipophilic ones in chloroform phase. Amounts equivalent to other extract phased tested for Raw seed Chloroform phase did not exerted any inhibition in human plasma oxidation

\subsection{In vitro anti-athirogenic activity}

The in vitro anti-atherogenic activity of Curcubita moschata seed extracts was evaluated as inhibition of human plasma oxidation and expressed as \% increase in lag time of human plasma oxidation in the presence of the tested sample compared to the reference sample with a lag time oxidation equal to $41.5 \mathrm{~min}$. An amount of water phase extract that corresponded to 22.5 $\mathrm{mg}$ of raw seeds caused an inhibition of human plasma oxidation, resulting in a lag time of 67.5 min that corresponded to a $63 \%$ increase compared to the reference sample. Non inhibition was detected for the chloroform phase of this extract. On the other hand, the water phase of the roasted seed extract, in an amount that corresponded to $15.2 \mathrm{mg}$ of roasted seeds, resulted in a lag time equal to $109.1 \mathrm{~min}$ that corresponded to a $163 \%$ increase compared to the reference sample. The chloroform phase of the roasted seed extract, in an amount that corresponded to $15.6 \mathrm{mg}$ of roasted seeds, was also active, causing a lag time of $142 \mathrm{~min}$ that corresponded to a $242 \%$ increase compared to the reference sample (Figure 7). The results show a higher in vitro anti-atherogenic activity for the extracts of the roasted seeds $(\mathrm{p}<0.05)$. These results mirror what was found for the total phenolic content and antioxidant capacity of the seed extracts.

The most common causes of death in westernized societies remain heart disease and stroke. Prevention of atherosclerosis is a major objective of modern medicine. Studies show that oxidation of plasma lipoproteins plays an important role in atherogenesis (Karten, Beisiegel, Gercken, \& Kontush, 1997), since oxidatively modified molecules on oxidized LDLs initiate the events of atherosclerosis development at the molecular level (Demopoulos et al., 2003). Therefore, the delay of plasma oxidation is a contributing protective factor against ahterogenesis. 


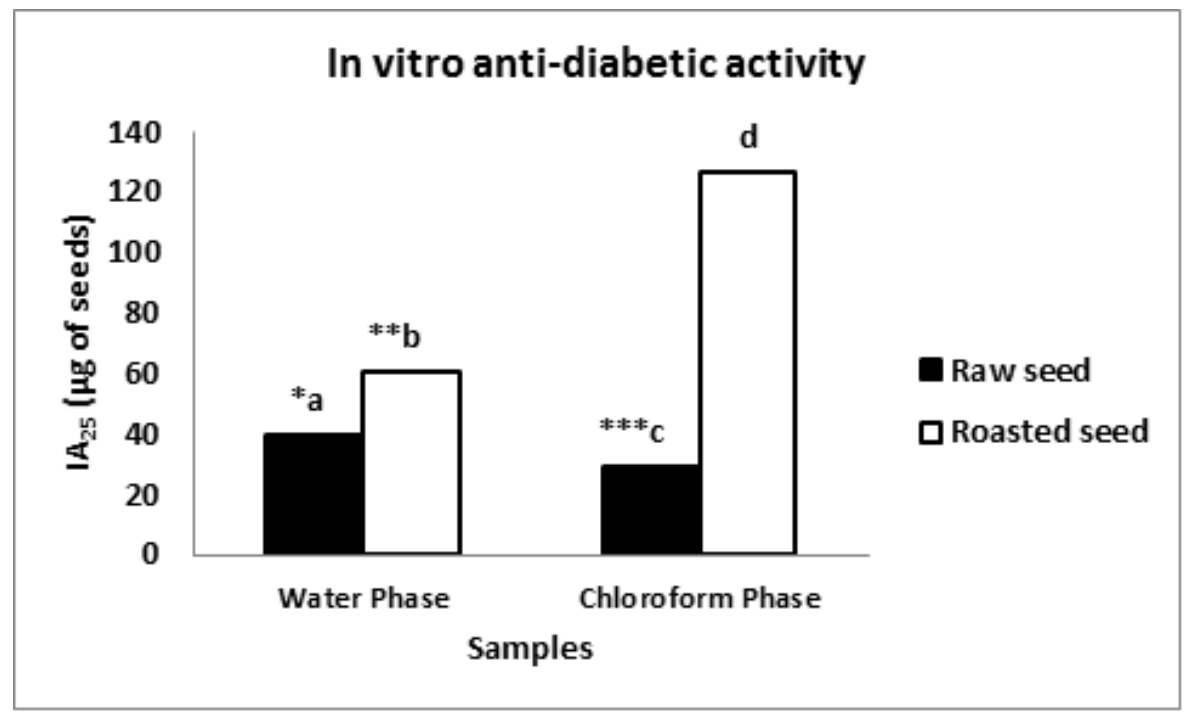

Figure 8: in vitro anti-diabetic activity as assessed by inhibition of alpha-glucosidase for raw and roasted pumpkin seeds extracted by methanol/water $70 / 30(\mathrm{v} / \mathrm{v})$ plus $2 \%(\mathrm{v} / \mathrm{v})$ acetic acid and separated as hydrophilic components in water phase and lipophilic ones in chloroform phase. The results are expressed as mean value for duplicate determinations in water and chloroform phase. $\mathrm{IA}_{25}$ : stands for equivalent amount for $25 \%$ inhibition. *: denotes significantly higher anti-diabetic activity compared to b and d and a lower one compared to c. ${ }^{* *}$ : denotes significantly higher anti-diabetic activity compared to d and a significantly lower one compared to c. ${ }^{* * *}$ : denotes significantly higher anti-diabetic activity compared to d.Differences with a value of $\mathrm{p}<0.05$ were considered statistically significant

\subsection{In vitro anti-diabetic activity}

The results of the ability of the extracts to inhibit alpha-glucosidase activity were expressed as the equivalent amount, in $\mu \mathrm{g}$ of seeds, for $25 \%$ inhibition of the enzyme $\left(\mathrm{IA}_{25}\right)$. This means that a lower value of $\mathrm{IA}_{25}$ corresponds to a higher inhibitory activity for the extract. The $\mathrm{IA}_{25}$ value of $40.0 \mu \mathrm{g}$ for the water phase of the raw seed extract was significantly lower compared to the value of $61.0 \mu \mathrm{g}$ for the respective phase of the roasted seed extract $(\mathrm{p}<0.05)$ (Figure 8). Similarly, $\mathrm{IA}_{25}$ of the raw seed extract chloroform phase, with a value equal to $29 \mu \mathrm{g}$ of seeds, was significantly lower compared to $127 \mu \mathrm{g}$ of seeds that corresponded to the $\mathrm{IA}_{25}$ value of the respective phase of the roasted seed extract $(\mathrm{p}<0.05)$ (Figure 8). The results show the existence of both hydrophilic and lipophilic minor compounds in both raw and roasted pumpkin seeds that exert anti-diabetic activity in terms of alpha-glucosidase inhibition, with a significantly higher activity of raw seed extracts $(\mathrm{p}<0.05)$. These results are in contrast to the rest of the results that show higher activities of roasted seed extracts compared to the raw ones.

One of the therapeutic approaches for treating diabetes is by controlling the postprandial hyperglycaemia by retarding the absorption of glucose. Enzyme alpha-glucosidase (EC 3.2.1.20), hydrolyses terminal non-reducing 1-4 linked alphaglucose residues to release a single alpha- glucose molecule creating in this way absorbable monosaccharides. Inhibition of alpha-glucosidase in the digestive tract delays carbohydrate digestion and prolongs overall carbohydrate digestion time. This causes a reduction in the rate of glucose absorption and consequently blunts the postprandial blood glucose and insulin levels. Thus alpha-glucosidase inhibitors may be an attractive therapeutic modality in type II diabetic patients (Bischoff, 1994; Jiang \& Du, 2011; 
Krentz \& Bailey, 2005; Lin et al., 2011; Oboh \& Ademosun, 2011).

\section{Conclusions}

Raw seed extracts from Cucurbita moschata exert antioxidant, anti-inflammatory/antithrombotic, anti-atherogenic and anti-diabetic activities. Anti-diabetic activity was detected higher in raw seed extracts. In contrast, the rest of the studied activities were increased by roasting the seeds. Experimental conditions for the roasting of the pumpkin seeds that would optimize total phenolic content and the rest of the studied activities is an area for further research.

The results show that in Lemnos Cucurbita moschata seeds there exists hydrophilic and lipophilic compounds with in vitro functionalities related to heath-beneficial effects. Pumpkin seeds appear to be a suitable candidate ingredient that, as an additive, may boost anti-oxidant anti-throbotic/anti-inflammatory capacities in certain novel functional food production of regional interest. Such functional foods would contribute in a sustainable way to public health improvement by reducing oxidative stress, thrombosis/ inflammation and the related chronic disease development.

\section{Acknowledgements}

We gratefully acknowledge the personel and the bacteriologist and manager of the Diagnostic Center Euromedica Iatriki of Lemnos, Mr Tsoukis Evaggelos for their cooperation in obtaining blood for PRP preparation.

\section{References}

Abe, N., Murata, T., \& Hirota, A. (1998). Novel oxidized sorbicillin dimers with 1,1diphenyl-2-picrylhydrazyl-radical scavenging activity from a fungus. Bioscience Biotechnology and Biochemistry, 62(11), 2120-2126. doi:10.1271/bbb.62.2120
Apak, R., Guclu, K., Ozyurek, M., \& Karademir, S. E. (2004). Novel total antioxidant capacity index for dietary polyphenols and vitamins $\mathrm{c}$ and e, using their cupric ion reducing capability in the presence of neocuproine: cuprac method. Journal of Agricultural and Food Chemistry, 52(26), 7970-7981. doi:10.1021/jf048741x

Arzamastseva, N. E., Lankin, V. Z., Konovalova, G. G., Tikhaze, A. K., Ageev, F. T., Lapina, V., ... Belenkov, Y. N. (2007). Oxidative stress in patients with chronic heart failure and type 2 diabetes mellitus. Bulletin of Experimental Biology and Medicine, 143(2), 207-209. doi:10.1007/ s10517-007-0052-8

Balagopal, P. (2006). Obesity-related cardiovascular risk in children and the role of lifestyle changes. Journal of the cardiometabolic syndrome, 1(4), 269-276.

Benzie, I. F. F. \& Strain, J. J. (1996). The ferric reducing ability of plasma (FRAP) as a measure of "antioxidant power": the FRAP assay. Analytical Biochemistry, 239(1), 7076. doi:10.1006/abio.1996.0292

Bischoff, H. (1994). Pharmacology of alphaglucosidase inhibition. European Journal of Clinical Investigation, 24(3), 310. Workshop on Alpha-Glucosidase Inhibitors in Diabetes, at the 27th Meeting of the European-Society-ofClinical-Investigation, HEIDELBERG, GERMANY, APR 14-17, 1993.

Bligh, E. G. \& Dyer, W. J. (1959). A rapid method of total lipid extraction and purification. Canadian Journal Of Biochemistry and Physiology, 37(8), 911-917.

Bourne, M. (2002). Food texture and viscosity: concept and measurement. (Chap. Texture, Viscosity and Food, pp. 1-32). Academic press.

Caili, F., Huan, S., \& Quanhong, L. (2006). A review on pharmacological activities and utilization technologies of pumpkin. Plant Foods For Human Nutrition, 61(2), 73-80. doi:10.1007/s11130-006-0016-6

Del Rio, D., Rodriguez-Mateos, A., Spencer, J. P. E., Tognolini, M., Borges, G., \& Crozier, A. (2013). Dietary (poly)phenolics in human health: structures, bioavail- 
ability, and evidence of protective effects against chronic diseases. Antioxidants E Redox Signaling, 18(14), 1818-1892. doi:10.1089/ars.2012.4581

Demopoulos, C. A., Karantonis, H. C., \& Antonopoulou, S. (2003). Platelet activating factor - a molecular link between atherosclerosis theories. European Journal of Lipid Science and Technology, 105(11), 705-716. doi:10.1002/ejlt.200300845

Demopoulos, C. A., Pinckard, R. N., \& Hanahan, D. J. (1979). Platelet-activating factor - evidence for 1-o-alkyl-2-acetyl-sn-glyceryl-3phosphorylcholine as the active component (a new class of lipid chemical mediators). Journal of Biological Chemistry, 254(19), 9355-9358.

Fragopoulou, E., Demopoulos, C. A., \& Antonopoulou, S. (2009). Lipid minor constituents in wines. a biochemical approach in the french paradox. International Journal of Wine Research, 1, 131-143. doi:10.2147/IJWR.S4587

Fuentes, Q. E., Fuentes, Q. F., Andres, V., Pello, O. M., Font de Mora, J., \& Palomo G, I. (2013). Role of platelets as mediators that link inflammation and thrombosis in atherosclerosis. Platelets, 24 (4), 255-262. doi:10.3109/09537104.2012.690113

Gawaz, M., Langer, H., \& May, A. E. (2005). Platelets in inflammation and atherogenesis. Journal of Clinical Investigation, 115(12), 3378-3384. doi:10.1172/JCI27196

Giacco, F. \& Brownlee, M. (2010). Oxidative stress and diabetic complications. Circulation research, 107(9), 1058-1070. doi:10. 1161/CIRCRESAHA.110.223545

Holt, E. M., Steffen, L. M., Moran, A., Basu, S., Steinberger, J., Ross, J. A., ... Sinaiko, A. R. (2009). Fruit and vegetable consumption and its relation to markers of inflammation and oxidative stress in adolescents. Journal of the American Dietetic Association, 109 (3), 414-421. doi:10.1016/j.jada. 2008.11.036

Jiang, Z. \& Du, Q. (2011). Glucose-lowering activity of novel tetrasaccharide glyceroglycolipids from the fruits of cucurbita moschata. Bioorganic \& Medicinal Chem- istry Letters, 21(3), 1001-1003. doi:10 . 1016/j.bmcl.2010.12.030

Kadam, P. V. \& Patil, M. J. (2014). Pharmacognostic study of cucurbita moschata (cucurbitaceae). Pharmacognosy Journal, 5, Supplement, 4-6. doi:10.1016/j.phcgj.2013.09. 002

Kadam, P. V., Yadav, K. N., Patel, A. N., Navsare, V. S., Bhilwade, S. K., \& Patil, M. J. (2012). Phytopharmacopoeial specifications of garcinia indica fruit rinds. Pharmacognosy Journal, 4(31), 23-28. doi:10. $5530 /$ pj.2012.31.5

Kampoli, A.-M., Tousoulis, D., Antoniades, C., Siasos, G., \& Stefanadis, C. (2009). Biomarkers of premature atherosclerosis. Trends in Molecular Medicine, 15(7), 323332. doi:10.1016/j.molmed.2009.06.001

Karantonis, H. C., Antonopoulou, S., \& Demopoulos, C. A. (2002). Antithrombotic lipid minor constituents from vegetable oils. comparison between olive oils and others. Journal of Agricultural and Food Chemistry, 50(5), 1150-1160. doi:10.1021/ jf010923t

Karantonis, H. C., Fragopoulou, E., Antonopoulou, S., Rementzis, J., Phenekos, C., \& Demopoulos, C. A. (2006). Effect of fast-food mediterraneantype diet on type 2 diabetics and healthy human subjects platelet aggregation. Diabetes Research and Clinical Practice, 72(1), 33-41. doi:10.1016/j.diabres.2005.09.003

Karantonis, H. C., Tsantila, N., Stamatakis, G., Samiotaki, M., Panayotou, G., Antonopoulou, S., \& Demopoulos, C. A. (2008). Bioactive polar lipids in olive oil, pomace and waste byproducts. Journal of Food Biochemistry, 32(4), 443-459. doi:10.1111/j.1745-4514.2008.00160.x

Karten, B., Beisiegel, U., Gercken, G., \& Kontush, A. (1997). Mechanisms of lipid peroxidation in human blood plasma: a kinetic approach. Chemistry and Physics of Lipids, 88(2), 83-96. doi:10.1016/S0009-3084(97) 00038-8

Koike, K., Li, W., Liu, L. J., Hata, E., \& Nikaido, T. (2005). New phenolic glycosides from the seeds of cucurbita moschata. Chemical 
and Pharmaceutical Bulletin, 53(2), 225228. doi: $10.1248 / \mathrm{cpb} .53 .225$

Krentz, A. J. \& Bailey, C. J. (2005). Oral antidiabetic agents - current role in type 2 diabetes mellitus. Drugs, 65(3), 385-411. doi:10.2165/00003495-200565030-00005

Li, F.-S., Dou, D.-Q., Xu, L., Chi, X.-F., Kang, T.-G., \& Kuang, H.-X. (2009). New phenolic glycosides from the seeds of cucurbita moschata. Journal of Asian Natural Products Research, 11(7), 639-642. doi:10. 1080/10286020902942376

Libby, P. (2007). Inflammatory mechanisms: the molecular basis of inflammation and disease. Nutrition Reviews, 65 (12, 2), S140S146. Conference on Living Well to 100 Is Inflammation Central to Aging, Tufts Univ, Boston, MA, NOV, 2006. doi:10 . 1301/nr.2007.dec.S140-S146

Lin, S.-D., Wang, J.-S., Hsu, S.-R., Sheu, W. H.-H., Tu, S.-T., Lee, I.-T., ... Hsieh, M.-C. (2011). The beneficial effect of alphaglucosidase inhibitor on glucose variability compared with sulfonylurea in taiwanese type 2 diabetic patients inadequately controlled with metformin: preliminary data. Journal of Diabetes and its Complications, 25(5), 332-338. doi:10.1016/j.jdiacomp. 2011.06.004

Merrick, L. M. (1990). Biology and utilization of the cucurbitaceae. In D. M. Bates, R. W. Robinson, C. Jeffrey, et al. (Eds.), (Chap. Systematics and evolution of a domesticated squash, Cucurbita argyrosperma, and its wild and weedy relatives, pp. 77-95). Cornell University Press.

Naelsen, C., Basu, S., Wolk, A., \& Vessby, B. (2006). The importance of dietary antioxidants on plasma antioxidant capacity and lipid peroxidation in vivo in middle-aged men. Scandinavian Journal of Food and Nutrition, 50(2).

Nasopoulou, C., Karantonis, H. C., Detopoulou, M., Demopoulos, C. A., \& Zabetakis, I. (2014). Exploiting the anti-inflammatory properties of olive (olea europaea) in the sustainable production of functional food and neutraceuticals. Phytochemistry Reviews, 13(2, SI), 445-458. doi:10.1007/ s11101-014-9350-8
Nomikos, T., Karantonis, H. C., Skarvelis, C., Demopoulos, C. A. ., \& Zabetakis, I. (2006). Antiatherogenic properties of lipid fractions of raw and fried fish. Food Chemistry, 96(1), 29-35. doi:10 . $1016 / \mathrm{j}$. foodchem.2005.01.060

Nomikos, T., Fragopoulou, E., \& Antonopoulou, S. (2007). Food ingredients and lipid mediators. Current Nutrition and Food Science, 3(4), 255-276.

Oboh, G. \& Ademosun, A. O. (2011). Shaddock peels (citrus maxima) phenolic extracts inhibit alpha-amylase, alpha-glucosidase and angiotensin i-converting enzyme activities: a nutraceutical approach to diabetes management. Diabetes \& Metabolic Syndrome: Clinical Research \& Reviews, 5(3), 148152.

Re, R., Pellegrini, N., Proteggente, A., Pannala, A., Yang, M., \& Rice-Evans, C. (1999). Antioxidant activity applying an improved ABTS radical cation decolorization assay. Free Radical Biology and Medicine, 26 (9-10), 1231-1237. doi:10 .1016 / S08915849(98)00315-3

Rondina, M. T., Weyrich, A. S., \& Zimmerman, G. A. (2013). Platelets as cellular effectors of inflammation in vascular diseases. Circulation Research, 112(11), 1506-1519. doi:10.1161/CIRCRESAHA.113.300512

Sabate, J., Ros, E., \& Salas-Salvado, J. (2006). Nuts: nutrition and health outcomes. British Journal of Nutrition, 96 (1, 2), S1S2. doi:10.1017/BJN20061857

Schnitzer, E., Pinchuk, I., Bor, A., Fainaru, M., Samuni, A. M., \& Lichtenberg, D. (1998). Lipid oxidation in unfractionated serum and plasma. Chemistry and Physics of Lipids, 92(2), 151-170. doi:10 . 1016 / S0009-3084(98)00021-8

Singleton, V. L. \& Rossi, J. A. (1965). Colorimetry of total phenolics with phosphomolybdic-phosphotungstic acid reagents. American journal of Enology and Viticulture, 16(3), 144-158.

Soong, Y. Y. \& Barlow, P. J. (2004). Antioxidant activity and phenolic content of selected fruit seeds. Food Chemistry, 88(3), 411-417. doi:10.1016/j.foodchem.2004.02. 003 
Functional activities of Lemnos Cucurbita moschata's seeds $\mid 237$

Vinholes, J., Grosso, C., Andrade, P. B., GilIzquierdo, A., Valentao, P., de Pinho, P. G., \& Ferreres, F. (2011). In vitro studies to assess the antidiabetic, anti-cholinesterase and antioxidant potential of spergularia rubra. Food Chemistry, 129(2), 454-462. doi:10.1016/j.foodchem.2011.04.098

Xanthopoulou, M. N., Fragopoulou, E., Kalathara, K., Nomikos, T., Karantonis, H. C., \& Antonopoulou, S. (2010). Antioxidant and anti-inflammatory activity of red and white wine extracts. Food Chemistry, 120(3), 665-672. doi:10.1016/j.foodchem.2009.10.058

Yen, G. C., Duh, P. D., \& Tsai, C. L. (1993). Relationship between antioxidant activity and maturity of peanut hulls. Journal of Agricultural and Food Chemistry, 41(1), 67-70. doi:10.1021/jf00025a015 